\title{
Role of Financial Institution on the Growth of Small and Medium Enterprises:-The Case in North Shewa Zone, Amhara Region, Ethiopia
}

\author{
Alebachew Goshim Azeref ${ }^{1}$, Yohanes Tefera Gelagil ${ }^{2}$ \\ ${ }^{1}$ Department of Accounting and Finance, Debre Birehan University, Debre Birehan, Ethiopia \\ ${ }^{2}$ Department of Logistics and Supply Chain Management, Debre Birehan University, Debre Birehan, Ethiopia \\ Email address: \\ alebachewgoshim $a$ gmail.com (A. G. Azeref), yohantef $@$ gmail.com (Y. T. Gelagil) \\ To cite this article: \\ Alebachew Goshim Azeref, Yohanes Tefera Gelagil. Role of Financial Institution on the Growth of Small and Medium Enterprises:-The \\ Case in North Shewa Zone, Amhara Region, Ethiopia. Journal of Investment and Management. Vol. 7, No. 5, 2018, pp. 143-150. \\ doi: $10.11648 /$ j.jim.20180705.12
}

Received: October 12, 2018; Accepted: October 29, 2018; Published: November 26, 2018

\begin{abstract}
The objective of this study was to investigate the role of financial institutions on the growth of small and medium enterprises and to give recommendations based on the problems. Despite the tremendous increase in number of SMEs, little research exists that examines role of financial institutions; banks and microfinance institutions; on the growth of small and medium enterprises in developing countries, especially in Ethiopia specifically in north shewa zone of Amhara region. SMEs occupy a prominent position in the development agenda of many developing countries like us. Primary data were collected from 102SMEs in north shewa zone. Data from the respondents was tabulated for descriptive purpose and analyzed and translated into useful information using the statistical package for social sciences (SPSS). Therefore the study identifies size of loan, lower borrowing cost and saving account has positive relationship with growth of small and medium enterprise and the influence of these variables was significant. On the other hand there was positive relationship between duration of loan, simplicity of criteria, follow up \& supervision and growth of SMEs. But the influence is relatively insignificance. The study recommends that the government and financial intuitions to make credit available and affordable to SMEs reducing the traditional barriers to SMEs financing, make financial intuitions products \& services without unattainable criteria and at lower borrowing cost, setup mechanisms of training for SMEs before and after the loan. The study also recommends that make saving account easily accessible facilitated with technology for their growth.
\end{abstract}

Keywords: Growth, Small and Medium Enterprises (SMEs), MFIs, Banks, Financial Institutions

\section{Introduction}

\subsection{Background of the Study}

Small and Medium Enterprises (SMEs), and financial institutions are very critical to the development of an economy. SMEs provide the vast majority of employment in developing countries and are keystones in the productive structures of emerging economies, such as; improvement of local technology, output diversification, development of indigenous entrepreneurship \& forward integration with large scale industries. Similarly in addition to providing substantial employment financial institutions play very prominent roles in firm's growth and industry productivity and economic growth. They conducts financing the small scale sector, development and support service in the form of loans \& grants to different agencies, availability of financial services to households \&individuals, insurance and financial services, managing risks by a diversity of financial instruments. Furthermore, financial institutions create financial assets for their customers and sell those assets to other market participants for a definite emolument. In addition to all these functions, financial institutions are also involved in providing investment advice to market participants and managing the portfolios of market participants [1]. Financial institutions play an extremely important role in economic development. Financial institutions cater to important needs of society such as taking care of small savings at reasonable rates. Everyday 
working men and women have the option of putting their savings into a number of alternatives such as Government small saving schemes, deposits into a saving account provided by their bank, recurring, deposits, time deposits and also the alternative option of investing in mutual funds or stocks.

In Ethiopia, the Ministry of Trade and Industry defined micro enterprises as business enterprises found in all sectors of the Ethiopian economy with a paid-up capital of not more than Birr 20,000 but excluding high-tech consultancy firms and other high-tech establishment while Small Enterprises are defined as business enterprises with a paid-up capital of more than Birr 20,000 but not more than Birr 500,000 but excluding high-tech consultancy firms and other high-tech establishments

The role that finance has as a lubricant for the real economy thus likewise exacerbates the effect of financial fragility on the real economy. The evidence has shown that finance has a more important impact on growth through fostering productivity growth and resource allocation than through pure capital accumulation [2]. Specifically, the availability of external finance is positively associated with entrepreneurship and higher firm entry as well as with firm dynamism and innovation. Finance is the life wire of any economy, whether developed or developing countries. Because of this financial institutions are one important drive for the growth of SMEs. Though human resources are the tool that propels any economic endeavor, but finance is very prominent after human resources. Finance is also known as capital, credit and so forth. Finance is to commercial pursuit as blood is to the human body. Finance is important to the survival and growth of SME [16]. On the other hand, there is limited evidence that confirms the role of financial institutions for the growth of SMEs. There for this research will significantly examine the role of financial institutions for the growth of SMEs in north shewa zone.

\subsection{Statement of the Problem}

Noticeably, SMEs are one of the leading forces of economic development particularly in the developing economies. This is because an energetic SMEs sector is vital to stimulate growth and job creation. SMEs are also flexible and can more easily be adapted to the demands of the market. They further generate jobs more rapidly than any other businesses, are highly diversified and contribute to exports and trade [21].

Long time in history development and expansion of SMEs was widely considered as sign of backwardness and lack of another alternative in all segments of the society. However; it is resulted from misunderstanding that SMEs are basis for a number of developments in technology sector of these days. With in this context SMEs is one of the institutions given recognition in the country's industry development plan and is the fact that it serves as vehicles for employment opportunities at urban center and as it emphasize the economic development. SMEs serve as sources for sustainable job opportunities not only for developing countries like ours, but also for developed countries like
USA. Thus the development of SMEs is the key component of Ethiopia's industrial policy direction that will contribute to the industrial development and economic transformation in Ethiopia. The development goal is specially secured on stimulating the rapid growth and structural transformation of the SMEs in ways that advance wealth creation and expansion of employment opportunity [20].

A crucial element in the development of the SME sector is access to finance, particularly to bank financing, given the relative importance of the banking sector in serving this segment. Firm-level data collected by the World Bank show that access to finance is perceived as one of the main obstacles to doing business $[14,21]$. A number of studies have shown that financing is a greater obstacle for SMEs than it is for large firms, particularly in the developing world, and that access to finance adversely affect the growth of the SME sector more than that of large companies [17, 2].

There are several factors that hinder potential growth of SMEs. Such factors are titled as growth barriers. It is argued that SMEs are more likely to face entry barriers and growth barriers compared to their large counterparts. Commonly addressed barriers for small businesses include institutional barriers and financial barriers. Institutional barriers are mainly discussed with the focus on firms' interaction with government, including legalization, taxation, and government support amongst others. Based on consistent results from both theoretical and empirical data, certain institutions intentionally discriminate against the growth of SMEs which in turn act as a growth barrier. It is not difficult to imagine that SMEs would have a tough period when they face unfavorable tax system, discriminatory regulations and complicated laws. Financial barriers represent lack of financial resources. It has been argued that credit constraints, lack of external debt, and equity capital are the main obstacles to the growth of SMEs. Evidence suggests that banks are more conservative when they provide loans to SMEs. Due to the information asymmetries, SMEs are more likely to be charged relatively high interest rates and asked for high collateral and loan guarantees. Furthermore, SMEs could also face external barriers, internal organizational barriers and social barriers which cover aspects of market position of a firm, access to qualified human capital, and access to network. Availability of financial capital is found to be crucial to firm growth $[5,8,12,18]$.

It is possible that firm growth is also affected by different types of barriers. These barriers can be divided into internal barriers, such as the motivation to grow, and external barriers. The most important external barriers for UK firms are the availability and cost of funding [19]. Many commentators have postulated a "financing gap" for SMEs, meaning that there are significant numbers of SMEs that could use funds productively if they were available, but cannot obtain finance from the formal financial system. This study analyses the "financing gap" concept, seeks to determine how prevalent such a gap may be - both in organization for economic cooperation \& development [OECD] countries and non-OECD economies, and recommends measures to foster an improved flow of 
financing to SMEs. While some surveys show that growth is not an objective for all small and medium sized firms, the ability of firms to grow is important, because it has been suggested that firms with low or negative growth rates are more likely to fail $[11,13]$.

This study differs from previous literature because of the variety of independent variables represented in the database. The growth rate with this paper is defined as growth of annual sales volume. A similar approach has previously been adopted. But that author used limited independent variables; provision of credit, training of the entrepreneur, and savings account, in addition that study excludes the role of banks [8]. However in this study includes the role of banks, because mostly accessibility of loan from MFIs benefited the MSEs and banks loan access for medium and large firms. Firm size, age of the firm and loan from banks are also used in the previous empirical studies as the measure of independent variables with panel data [4].

While most studies in the field investigate growth in employment. The researcher chooses the measure sales volume, because firms rarely select employment growth as their goal per se. It could also be argued that the sample of SMEs justifies this choice even more due to the excessively high labor cost imposed on local employers, these costs are often stated to be a major barrier for small firms to increase the number of their employees. SMEs provide the vast majority of employment and key stone in the productive structure of emerging economies in developing countries, but the growth of such firms is being hindered by scarce financing.

SMEs to be the major pivot of economic growth and development of the country must be adequately financed. In order to provide consumers and commercial clients with a wide range of services and different types of banking, especially to small business, the Ethiopian government has evolved a wide variety of financial institutions both at the national and regional level as an effective means of fighting unemployment and income inequality. Based on this the purpose of this study were to determine and identify the role the financial institutions in the growth of SMEs and how provision of credit, training, simplicity of criteria, follow up and supervision, borrowing cost, size of loan, duration of loan and savings account influences the growth of Small and medium enterprises.

\subsection{Objectives of the Study}

\subsubsection{General Objective}

The general objective of the study is to find out the role of financial institutions, especially on banks and Microfinance institutions on the growth of small and medium enterprises in north shewa zone.

\subsubsection{Specific Objectives}

Specific Objectives of the study are:-

a) To assess the products of financial institutions are reasonably priced for the SMEs.

b) To find out the effect of different variables on the growth of SMEs

\section{Method}

\subsection{Research Design}

The primary aim of this study is to examine the role of financial institutions in SMEs growth. To achieve this objective a mixed method (both quantitative and qualitative) were adopted. The purpose of using such methods is to gather data that could not be obtained by adopting a single method and for triangulation so that the findings with a single approach were substantiated with others wherever possible.

\subsection{Population and Sampling Design}

The sampling frame for the planned research was 815 small and medium enterprises out of the total population of 11,244 SMEs which were registered in north shewa zone. Stratified random sampling technique was used in selecting SMEs. This sampling technique enables the researchers to generalize their findings and make inferences from a sample, thus enabling one to draw conclusions about a population. Finally 102 SMEs were proportionally selected from each business activities.

\subsection{Types and Sources of Data}

The necessary data for this study were collected from primary sources. The primary data were obtained through questioner, which contains open and closed ended questions. A structured questionnaire designed to collect the required data for this study on a likert type scale. The 5-point rating scale of strongly agree, agree, I have no idea, disagree and strongly agree.

\subsection{Specification of Empirical Research Model}

To estimate the impact of financial institutions; banks and MFIs on the growth of SMEs, the following general empirical research model is developed:

$$
\mathrm{Y}=\beta \mathrm{o}+\beta \mathrm{kX}+\mathrm{C}
$$

Where:

Y represents the mean value of dependent variable- fiscal sales volume

$\beta$ o is the intercept

$\beta \mathrm{k}$ represents the coefficients of the $\mathrm{X}$ variable

$\mathrm{X}$ represents the explanatory variables (Simplicity of criteria, Borrowing cost, size of loan, Duration of loan, Training, Savings account and follow up supervision)

$C$ is the error term

\subsection{Dependent and Independent Variables of Factor Considerations}

\subsubsection{Dependent Variables}

Dependent variables in this study are the variables which are used to measure the growth of small and medium enterprises such as sales volume. This is because growth in sales reflects both short term \& long term changes in a firm $\&$ it easy to obtain. 


\subsubsection{Independent Variables}

Simplicity of criteria: -Determined by different processes which is time taking, and difficult to understand. Accessibility to credit affects financial performance of Small enterprises positively. The easier it is to access credit, the higher the financial performance of the Small and medium enterprises [8].

Duration of loan:-non availability of medium or long term credit particularly for medium size enterprises is a major constraint for those enterprises that wish to expand their activities [3].

Size of Loan: -Ensuring adequate access to finance so that Small and medium enterprises can grow and achieve their full potential is central to achieving the objectives of the renewed Lisbon partnership for growth and jobs [2, 17].

Borrowing cost: - the cost which is paid by the borrower to get the loan small firms face specific constraints in raising external finance. It difficult to obtain outside capital in small amount and when they are able to obtain debt capital, it is at high interest rates. A major constraint of small business is its inability to obtain adequate financing, either in an absolute sense or because the cost; in terms of interest rates is often prohibitive. He further argues that the high cost of small business borrowing has put considerable pressure on small business marginal profits [2, 17].

Savings account: Adverse saving behavior and low savings present a crucial reason for a country being kept in a poverty trap. The image of a microfinance institution produced by experience can increase local trust, which can enhance the willingness to accept credit and therefore promote savings, as well. If these factors (and first and foremost microcredit) have a significant effect on savings, then microfinance institutions do contribute to development within a country [9].

Training and assistance: Which is given by Banks and MFIs to small and medium enterprises is crucial for successful performance of enterprises. Management competence encompasses functional knowledge, management skills and managerial behavior. Thus, competencies such as marketing, financial control, training and networking among others, are management functions, although in many studies, the success of the informal sector pivot on the managerial skills of the entrepreneurs who are attracted to the sector due to the relative low investment and service costs required. Training was found to be playing a crucial small and medium enterprise in growth of small and medium enterprises, especially in assisting the businesses to repay back their loans in order to get more credit in future $[8,10]$.

Follow up and supervision: Which is made by financial institutions to confirm the SMEs uses the loan based on the proposal.

\section{Result and Discussion}

\subsection{Role of Banks and MFIs in the Growth of SMES}

Borrowing from the commercial banks is herculean to the SMEs. The bank does not also have the reach in terms of branches, neither does it have the capacity for lending, nor the information technology platforms and human resources requirement. The Bank does not even address the issue of how to get credit to the SMEs [15]. The prospective of microfinance is to broaden access to financial services for lower income levels and increases the amount of undertaken productive projects. By inclusion into the financial sector, improved income-generation is predicted. MFIs are supposed to be different from other financial institutions in that they are believed (and particularly established) to serve the microfinance needs of those who are underserved by banks [4].

Table 1. Access to Bank and MFIs loans.

\begin{tabular}{lllll}
\hline $\begin{array}{l}\text { Access to } \\
\text { loans }\end{array}$ & Banks & \multicolumn{3}{c}{ MFIs } \\
\cline { 2 - 5 } & Frequency & Percent & Frequency & Percent \\
\hline Yes & 32 & 31.4 & 92 & 90.2 \\
No & 70 & 68.6 & 10 & 9.8 \\
Total & 102 & 100 & 102 & 100 \\
\hline
\end{tabular}

Sources: SMEs survey, 2018

As indicated above in table 1 of the second column indicates that $31.4 \%$ of SMEs respondents had access to financial resources, and the remaining $68.6 \%$ had no access to financial resources from banks. And third column indicates that $90.2 \%$ of SMEs respondents had access to financial resources, and the remaining $9.8 \%$ had no access to financial resources from MFIs.

Table 2. Reasons for not having access to Bank \& MFIs Loans(Multiple answers were possible).

\begin{tabular}{lllll}
\hline Reasons for not & Banks & \multicolumn{3}{l}{ MFIs } \\
\cline { 2 - 5 } having loans from & Frequency & percent & Frequency & percent \\
\hline Inadequate collateral & 25 & 78.1 & 36 & 39.1 \\
Fear of loan repayment & 1 & 3.1 & 10 & 10.9 \\
Higher interest rate & 6 & 18.8 & 46 & 50 \\
\hline
\end{tabular}

Sources: SMEs survey, 2018

The respondents were also asked to justify reasons for not having bank and MFI loans. The study result in the above table 2 shows in the second column, that $78.1 \%$ respondents justify thatthe collateral required by banks from the borrowers is not adequate. That means it does not consider the economic capability of borrowers. The lending interest rate is the second highest factor that hinder borrowers access to loan from banks (which constitute $18.8 \%$ of total respondents). The remaining $3.1 \%$ of respondents fear the loan repayment so they do not want to borrow money from banks.

At the same table with column three related to MFIs, $39.1 \%$ of respondents justify that there is high collateral requirement by MFI which is inadequate for borrowers and $50 \%$ of respondents said that since the lending interest rate of MFI is high even above the lending interest rate of most banks in Ethiopia it hinder us to borrow money from MFI. The remaining $10.9 \%$ of respondents fear the repayment of loan and this become a cause for them not to ask borrowing even if they are in working capital shocking.

Generally as indicated from the table 2 above the collateral requirement by banks hinder SMEs to access loan from 
banks than MFIs, this is mainly because MFIs have group lending mechanisms for SMEs, if individual have no collateral. To the reverse the interest rate of banks was not much the reason for not having loan from banks than MFIs. This is because the interest rate of MFIs is higher than Banks.

Table 3. Contribution of Banks \& MFIs loan to SMEs Growth on Sales Volume.

\begin{tabular}{lllll}
\hline Contribution of loan to SMEs & Banks & \multicolumn{3}{l}{ MFIs } \\
\cline { 2 - 5 } growth on sales volume & Frequency & Percent & Frequency & Percent \\
\hline Agree/ Strongly agree & 29 & 90.6 & 88 & 95.6 \\
I have no idea & 0 & 0 & 1 & 1.1 \\
Disagree/ Strongly disagree & 3 & 9.4 & 3 & 3.3 \\
Total & 32 & 100 & 92 & 100 \\
\hline
\end{tabular}

Sources: SMEs survey, 2018

As can be seen from table 3 of second column, SMEs that applied and received loan were asked about the contribution of loan for their growth, to distinguish whether the loan had contribution to their growth or not. Based on this $90.6 \%$ of respondents strongly agreed and agreed that contribution of bank loan is very high for the growth of SMEs. On the other hand $9.4 \%$ of respondents said that contribution of bank loan to the growth of SMEs is nothing.

The respondents were also asked to justify the contribution of MFIs loan on the growth of their firm. The result in the third column shows that, $95.6 \%$ of the total respondents believe that the contribution of MFIs loan to the growth of SMEs is very high that is MFIs loan has positive influence on growth of SMEs. On the other hand $3.3 \%$ of respondents strongly disagree and disagree on the contribution of loan by MFIs to the growth of SMEs. And the remaining $1.1 \%$ of respondents have no idea about the impact of MFIs loan on the growth of SMEs.

Table 4. Duration of Banks \& MFIs Loans.

\begin{tabular}{lllll}
\hline Enough duration of & Banks & \multicolumn{3}{l}{ MFIs } \\
\cline { 2 - 5 } loans repayment & Frequency & Percent & Frequency & Percent \\
\hline Agree /Strongly agree & 7 & 21.9 & 30 & 32.6 \\
I have no idea & 0 & 0 & 1 & 1.1 \\
Disagree/ Strongly disagree & 25 & 78.1 & 61 & 66.3 \\
Total & 32 & 100 & 92 & 100 \\
\hline
\end{tabular}

Sources: SMEs survey, 2018

Non availability of medium or long term credit particularly for medium size enterprises is a major constraint for those enterprises that wish to expand their activities [3]. In this regard as the study result indicate in the table 4 above the repayment period given by banks and MFIs is not enough.

With this regard $78.1 \%$ of respondents Disagreed/ Strongly disagreed and only $21.9 \%$ of respondents Agreed /strongly agreed that the maturity period given by banks for loan repayment is enough. Also while they are looking to column three of table 4 above $66.3 \%$ of respondents Disagreed/ Strongly disagreed with regard to duration of loan repayment. This means that the loan repayment period given by MFIs to the borrowers is not enough. On the other hand $32.6 \%$ of respondents are agreed and strongly agreed on the maturity period of the loan. The remaining $1.1 \%$ have no idea about the issue. Generally the loan repayment period given by banks and MFIs to SMEs is not enough. This indicates that banks and MFIs found in the study area are not contributing to the growth of SMEs as expected.

Table 5. Simplicity of Banks \& MFIs Loan Criteria.

\begin{tabular}{lllll}
\hline \multirow{2}{*}{ Simplicity of Criteria } & Banks & \multicolumn{3}{l}{ MFIs } \\
\cline { 2 - 5 } & Frequency & Percent & Frequency & Percent \\
\hline Agree /Strongly agree & 4 & 12.5 & 31 & 33.7 \\
I have no idea & 0 & 0 & 2 & 2.2 \\
Disagree/ Strongly disagree & 28 & 87.5 & 59 & 64.1 \\
Total & 32 & 100 & 92 & 100 \\
\hline
\end{tabular}

Sources: SMEs survey, 2018

The table above shows the inquiries result about simplicity of banks and MFIs loans criteria,

As shown at second column $87.5 \%$ respondents strongly disagreed and disagreed. That means criteria set by banks to provide or to give loan to SMEs is complex, time taking and difficult to understand. This will result banks not to contribute to the growth of SMEs as expected. Only $12.5 \%$ of respondents agreed and strongly agreed that the criteria set by banks is simple and understandable to borrowers (SMEs). On the other hand the majority respondents (64.1\%) justify that the criteria set by MFIs to give loan to SMEs is still not simple and understandable. Thai is they disagreed and strongly disagreed. Off course relative to banks loan criteria, the loan criteria set by MFIs is relatively simple and understandable but it does not mean that loan criteria of MFIs is good. On the other hand $33.7 \%$ of respondents believe that the criteria set by MFIs are simple and understandable to borrowers (SMEs).

Table 6. Size of Banks \& MFIs Loans.

\begin{tabular}{lllll}
\hline \multirow{2}{*}{ Size of loans } & Banks & \multicolumn{3}{l}{ MFIs } \\
\cline { 2 - 5 } & Frequency & Percent & Frequency & Percent \\
\hline Agree /Strongly agree & 9 & 28.1 & 32 & 34.8 \\
I have no idea & 0 & 0 & 5 & 5.4 \\
Disagree/ Strongly disagree & 23 & 71.9 & 55 & 59.8 \\
Total & 32 & 100 & 92 & 100 \\
\hline
\end{tabular}

Sources: SMEs survey, 2018

Ensuring adequate access to finance so that Small and medium enterprises can grow and achieve their full potential is central to achieving the objectives of the renewed Lisbon partnership for growth and jobs. Kauffmann suggests that securing suitable financing remains an obstacle for Small and Medium Enterprises, especially for the growth of innovative Small and Medium Enterprises, In this regard as indicated in the table 6 above majority SMEs in the study area does not have adequate amount of loan from banks. As shown in the table above only $28.1 \%$ of respondents can get adequate size of loan from banks the remaining $71.9 \%$ SMEs does not have adequate size of loan from banks which are found around them.

The number of SMEs that can get adequate size of loan from MFI is also not more than $34.8 \%$ as indicated in the 
table above. Still $59.8 \%$ of SMEs does not have adequate size of loan from MFIs found around them. This shows the contribution of financial institution for the growth of SMEs is very low and poor and need to be improved.

Table 7. Trainings offered by Banks \& MFIs

\begin{tabular}{lllll}
\hline \multirow{2}{*}{ Trainings offered } & Banks & \multicolumn{3}{l}{ MFIs } \\
\cline { 2 - 5 } & Frequency & Percent & Frequency & Percent \\
\hline Agree /Strongly agree & 9 & 28.1 & 26 & 28.3 \\
I have no idea & 0 & 0 & 0 & \\
Disagree/ Strongly disagree & 23 & 71.9 & 66 & 71.7 \\
Total & 32 & 100 & 92 & 100 \\
\hline
\end{tabular}

Sources: SMEs survey, 2018

That training which is given by Banks and MFIs crucial for the growth of small and medium enterprises since it is an input for the successful performance of enterprises. The financial institutions may deliver training for borrowers (SMEs in our case) in regard to management competence encompass functional knowledge, management skills and managerial behavior [8, 10]. According to respondents opinion the basic problems of banks and MFIs found in the study area is they does not provide continuous training and supervision for SMEs. Only $28.1 \%$ of SMEs respondents are agreed and strongly agreed that the bank provide continuous training and supervision for SMEs.. The remaining $71.9 \%$ of SMEs respondents are saying banks does not provide continuous training and supervision for SMEs.

Similarly only $28.3 \%$ of SMEs respondents are agreed and strongly agreed that MFIs are providing continuous training and supervision for SMEs. The remaining $71.7 \%$ of SMEs respondents are dissatisfied (disagreed and strongly disagreed) by MFIs training and supervision since it was not continuous and helpful for their business. Generally the result shows that the contribution of financial institutions especially banks and MFIs to the growth of SMEs in providing continuous training and supervision were very poor.

Table 8. Follow Up \& Supervision of Banks\& MFIs.

\begin{tabular}{lllll}
\hline \multirow{2}{*}{ Follow up \& supervision } & Banks & \multicolumn{3}{l}{ MFIs } \\
\cline { 2 - 5 } & Frequency & Percent & Frequency & Percent \\
\hline Agree /Strongly agree & 8 & 25 & 48 & 52.2 \\
I have no idea & 0 & 0 & 2 & 2.2 \\
Disagree/ Strongly disagree & 24 & 75 & 42 & 45.6 \\
Total & 32 & 100 & 92 & 100 \\
\hline
\end{tabular}

Sources: SMEs survey, 2018

Follow up and supervision made by financial institutions is important for the growth of SME. In this regard the survey result in table 8 of the second column shows that $48 \%$ of the respondents were strongly agree and agree with follow up and supervision offered by banks. Whereas $42 \%$ of respondents were disagree and strongly disagree with the statement.

Table 8 of the third column shows that $52.2 \%$ of the respondents were strongly agree and agree with follow up and supervision offered by MFIs. Whereas $45.6 \%$ of the respondents were disagree and strongly disagree with the statement.

Table 9. Lower Borrowing Cost of Banks \& MFIs.

\begin{tabular}{lllll}
\hline \multirow{2}{*}{ Lower borrowing cost } & \multicolumn{3}{l}{ Banks } & \multicolumn{3}{l}{ MFIs } \\
\cline { 2 - 5 } & Frequency & Percent & Frequency & Percent \\
\hline Agree /Strongly agree & 3 & 9.4 & 7 & 7.6 \\
I have no idea & 0 & 0 & 0 & 0 \\
Disagree/ Strongly disagree & 29 & 90.6 & 85 & 92.4 \\
Total & 32 & 100 & 92 & 100 \\
\hline
\end{tabular}

Sources: SMEs survey, 2018

As can be seen from the table 9 of column two, for the inquiry lower borrowing cost of the bank, $9.4 \%$ of the respondents strongly agree and agree. $90.6 \%$ of the respondents were disagree and strongly disagree. Which implies that to acquire the bank loan most of SMEs were incurred very higher cost.

Also the survey result in the table 10 of column three, for the inquiry about lower borrowing cost of the MFIs, 7.6\% of the respondents strongly agree and agree. $92.4 \%$ of the respondents were disagree and strongly disagree. Which implies that to acquire the MFIs loan most of SMEs were incurred higher cost.

The study shows that there is higher borrowing costs incurred, which negatively affect the growth of SME.

\subsection{Regression Results}

This section employs econometric analysis to ascertain the role of financial institutions. Although statistical computation has been used, the compelling reason for using a regression technique is that it estimates the impact of each explanatory variable after allowing variations in the dependent variables. The regression is the result of questionnaire results of dependent variable \& independent variables. In this section the researchers tries to analyzing the impact of each independent variable on the dependent variable.

Table 10. Regression Result of Multivariable.

Model Summary

\begin{tabular}{lllll}
\hline Multiple R & R Square & Adjusted R Square & Standard error of the estimate & 0.63195 \\
\hline 0.824 & 0.678 & 0.642 & & \\
\hline ANOVA (Analysis of variance) & & & & \\
\hline & & & Mean square & F \\
\hline Regression & Sum of squares & Df & 7.546 & 18.893 \\
Residual & 52.814 & 7 & .398 & $.000 \mathrm{a}$ \\
Total & 25.160 & 63 & & \\
\hline
\end{tabular}




\begin{tabular}{|c|c|c|c|c|c|c|}
\hline Variables & B & Std. Error & Beta & $\mathbf{T}$ & Sig. & VIF \\
\hline Duration of loan & 0.146 & 0.099 & 0.151 & 1.481 & 0.145 & 2.016 \\
\hline Criteria to be met & 0.022 & 0.095 & 0.023 & 0.222 & 0.827 & 1.971 \\
\hline Size of loan & 0.242 & 0.091 & 0.281 & 2.672 & 0.011 & 2.145 \\
\hline Follow up and supervision & 0.103 & 0.090 & 0.101 & 1.149 & 0.256 & 1.486 \\
\hline Lower borrowing cost & 0.198 & 0.077 & 0.204 & 2.585 & 0.013 & 1.203 \\
\hline Saving account & 0.386 & 0.099 & 0.400 & 3.928 & 0.000 & 2.017 \\
\hline Training & 0.022 & 0.068 & 0.029 & 0.305 & 0.763 & 1.645 \\
\hline
\end{tabular}

\section{Duration of Loan}

As can be seen from the table the coefficient or beta value of duration is positive, but its influence on SMEs growth was insignificant. In addition, the t-value and $\mathrm{p}$-value support this argument. Which means t-value is 1.481 which is less than 2 . As the p-value indicated it is 0.145 which is much greater than 0.05 . These two tests support that the Impact of duration of loan is statistically insignificant.

\section{Criteria to be Meet}

The result indicates that, simplicity of criteria has a positive effect on the growth of SMEs. Simplicity of criteria explains the variation of growth of SMEs with beta value of 0.023 , which is positive but insignificant, also the t-value 0.222 which is by far less than 2 , which is the rule of thumb to test statistical significance using t-value. Moreover, pvalue 0.827 is greater than 0.05 . Although simplicity of criteria associates with SMEs growth positively, it is insignificant based on $\mathrm{t}$ and $\mathrm{p}$ values.

\section{Size of Loan}

As can be seen from the table, size of loan has a positive significant contribution on the growth of SMEs next to saving account among the variables included in this model. Size of loan explains the variation of the growth of SMEs with a coefficient of or beta value of 0.281 which is statistically significant at 5\% level of significance. This means holding other variables constant for a unit change of the size of loan there is a $28.1 \%$ change (growth) in SMEs. In addition, the $\mathrm{t}$ value and $\mathrm{p}$ value support its statistical significance. According to 2-t rule of thumb the t-value should be greater than 2 to be statistically significant.

Here its t-value is 2.672 which are greater than 2 . The Pvalue in the above table, which is 0.011 , it is less than 0.05 . These two tests support the statistical significance of the size of loan on the growth of SMEs.

\section{Follow Up \& Supervision}

As it is seen from the regression result, though insignificant, it has a positive contribution to the growth of SMEs. Follow up and supervision explains the variation of the SMEs growth with a coefficient or beta value of 0.101 which is statistically insignificant at $5 \%$ level of significance. In addition, the t-value and p-value support its statistical insignificance.

The t-value is 1.149 which is less than 2 , which is used a t-test for statistical significance according to rule of thumb of 2-t. By the same token the p-value is 0.256 which is greater than 0.05 . Thus, there is an insignificant positive relationship between Banks \& MFIs follow up \& supervision and SMEs growth.

\section{Lower Borrowing Cost}

As can be seen from the table, lower borrowing costs Banks and MFIs have a positive effect on the growth of SMEs. Lower borrowing cost explains the variation of the growth of SMEs with a coefficient of or beta value of 0.204 which is statistically significant at $5 \%$ level of significance. This means holding other variables constant for a unit decrease of the borrowing cost there is a $20.4 \%$ change (growth) in SMEs. In addition, the $t$ value and $\mathrm{p}$ value support its statistical significance. According to 2-t rule of thumb the t-value should be greater than 2 to be statistically significant. Here its t-value is 2.585 which is greater than 2 . When we see the P-value, which is 0.013 , it is less than 0.05 . These two tests support the statistical significance of the impact of lower borrowing costs on the growth of SMEs.

\section{Saving Account}

As it is seen from the regression result, saving account from Banks and or MFIs have a positive effect on the growth of SMEs. Saving account explains the variation of the growth of SMEs with a coefficient of or beta value of 0.400 which is statistically significant at $5 \%$ level of significance. This means holding other variables constant for a unit increase in saving account there is a $40 \%$ change (growth) in SMEs. Also the t-value 3.928 which is greater than 2, it is the rule of thumb to test statistical significance using t-value. Moreover, p-value 0.000 indicates that greater than 0.05 . These two tests support the statistical significance of the impact of saving account on the growth of SMEs.

\section{Training}

The result indicates that, training has a positive effect on the growth of SMEs. Training explains the variation of growth of SMEs with beta value of 0.029 , which is positive but insignificant, also the t-value 0.305 which is by far less than 2, which is the rule of thumb to test statistical significance using t-value. Moreover p-value 0.763 is greater than 0.05. Although training associates with SMEs growth positively, it is insignificant based on $t$ and $p$ values. It is advisable that accessibility of training should positively related to the growth of SMEs [8].

\section{Conclusion}

This study investigates the role of financial institution on the growth of SMEs by taking evidence from SMEs, which is in north shewa zone.

Based on the results of descriptive statistics, correlation and regression analysis, the researchers made the following 
conclusions:

The primary contribution to existing literature by this study is an indication of a relationship between role of financial institutions, particularly, banks and MFIs in terms of duration of loan, simplicity of criteria, size of loan, follow up and supervision, lower borrowing cost, saving account and training, and SMEs growth in terms of sales volume. Not much research has been done to examine the role of financial institutions in the growth of SMEs in our country. In that sense, the result best serves as an input for discussion on financial institutions products and services accessibility for policy makers and FIs itself.

The study findings indicated that, there was positive relationship between duration of loan and growth of SMEs. But the influence is relatively insignificance. Simplicity of criteria is one of the variables in the study and the study result revealed that there is positive relationship between the growth of SME and this variable but the influence of the variable remain insignificant. Similarly the follow up and supervision provided by financial institutions to SME also have positive effect on the growth of SME even if the influence is insignificant. Training also has the same relationship and influence like duration of loan, simplicity of criteria and size of loan. On the other hand size of loan, lower borrowing cost and saving account has positive relationship with growth of small and medium enterprise and the influence of these variables was significant.

\section{Recommendations}

The SMEs, for it to be the major axle of economic growth and development of the country, must be adequately financed. Financial institutions need to strengthen their accessibility of products and services for them.

The study recommends that financial institutions assist SMEs without strict and unattainable criteria or make the criteria simple and attainable, also at a lower borrowing cost to make their products accessible and available. Financial institutions employ creative procedures to hold down their costs. Set up mechanisms of training where all SMEs should be trained before advanced with loans and after to enhance growth and reduce rates of default. The study recommends further on financial institutions develop follow up and supervision system after the loan provided to SMEs. Make savings account cheaper and easily accessible facilitated with technology. The government should also establish special fund for SMEs, which will be easily accessible and attainable. In order to promote the development andgrowth of SMEs financial institutions must access loan adequately.

\section{References}

[1] Mehreen Mishah; [2014] what is the role of financial institutions in economic development?
[2] Beck et al., [2005, 2006] Financial and legal constraints to firm growth.

[3] Dagva Boldbaatar, (2005) Role of central bank in promoting SME.

[4] Dereje Workie Nigussie, February, [2012] Role of Financial Institutions in the Growth of Small and Medium Enterprises in Addis Ababa.

[5] Haibo Zhouh, Gerrit de Wit, February [2009] Determinants \& Dimensions of firm growth; Zoetermecr.

[6] James Milford, [2014] what is the role of financial institutions in economic development?

[7] James Wambua Nganda, Kadian W. Wanyonyi and Elizabeth M. Kitili, 21 January [2014] Determinants of growth of small and medium enterprises in Kakamega central sub-county, Kenya, University of Nairobi, Kenya.

[8] Kepha Momany, Osoro Jomo, [2013] The role of Micro Finance Institution on the growth of SMEs in Kenya; a case study of MFIs in Kisi Town; IOSR Journal of Humanities and social science[IOSR-JHSS-pp 83-93].

[9] Amelie Brune, August 21,[2009] An empirical study on the impact of microfinance institutions on development.

[10] Naituli, G., Wegulo, Francis N. \&Kaimenyi, B., [2006] Entrepreneurial Human Capital and Growth of Micro and Small Scale Women enterprises in Rural Kenya.

[11] OECD, [2006] Organization for Economic Cooperation \& Development; The SME Financing Gap; Theory and Evidence.

[12] Per Davidsson and Magnus Henerksson, [2002] Institutional determinants of the prevalence start ups and high growth firms.

[13] Phillips, B., and B. Kirchhoff, [1989] Formation, growth and survival; Small firm dynamics in the US economy, Small Business Economics 1, 6567.

[14] Pieto calic, Victor M. Chando \& Sofian Sekioua, March [2012] Bank Financing to SME in East Africa; Findings of survey in Kenya, Tanzania, Uganda \& Zambia.

[15] Radwan, A., [2009] An evaluation of the challenges and prospects of micro and small scale enterprises development in Nigeria. American international journal of contemporary research, 2, 4, 174-185.

[16] Robinson O. Owenvbiugie; [2014] Role of finance on the growth of SMEs. In Edo state of Nigeria.

[17] Shiffer \& Wede, [2001] Firm size and business Environment; worldwide survey results.

[18] Stiglitz \& Weiss, [1981] Credit rationing in markets with imperfect information; American Economic Review.

[19] Storey, D., [1994] Understanding the small business sector, Routledge, New York.

[20] UNDP, June [2012] Entrepreneurship Development Program in Ethiopia; Addis Ababa Ethiopia.

[21] World Bank Report [2005, 2014]. 